\title{
Les isoflavones du soja dans la filière aliment santé
}

\section{Soya isoflavonoids in the health food chain}

Oléagineux, Corps Gras, Lipides. Volume 7, Numéro 3, 287-96, Mai - Juin 2000, Fondamental

Auteur(s) : Stéphanie LACOMBE, Vassilia THÉODOROU-BAYLE, Philippe LA DROITTE, Jean DAYDE, .

Résumé : Plusieurs études ont mis en évidence les propriétés alicamenteuses des isoflavones du soja. Ces propriétés leur confèrent un potentiel de prévention vis-à-vis des maladies cardio-vasculaires, de certains cancers et des problèmes en lien avec la ménopause. Cependant, des influences néfastes au niveau, notamment, du développement reproducteur et de la fertilité de plusieurs espèces animales ont été établies. Des différences de biodisponibilité et de métabolisme de ces composés bioactifs ont été observées entre individus mais également entre les différentes isoflavones du soja (12 isoflavones différentes ont été isolées dans les graines et les produits à base de soja). Par ailleurs, plusieurs facteurs en lien avec le génotype et le milieu de culture influencent la teneur et la composition de ces composés dans la graine. Enfin, les procédés de production affectent également la teneur et/ou la composition en isoflavones dans les produits à base de soja.

Mots-clés : soja, isoflavones, composés « santé ", daidzéine, génistéine, phyto-œstrogènes, variabilité, effets de l'environnement.

Summary: Health promoting activities of isoflavones have been observed by many authors. These activities are potentially able to prevent the development of cardiovascular diseases, hormonodependant cancers and menopausal diseases. Several animal studies have, however, reported adverse influences on reproductive development and fertility. Differences of bio-availability and metabolism are observed among individuals and among soybean isoflavones. Twelve isoflavones have been isolated in soybean seeds and soyfoods. Moreover, several factors influence the content and the composition of these health compounds in raw material. Transformation processes, also, affect isoflavone content and/or composition in soybean foods.

Keywords: soybean, isoflavones, health compounds, daidzein, genistein, phytoestrogens, variability, environment effects.

\section{ARTICLE}

\section{Introduction et généralités}

Les isoflavones sont les principaux composés phénoliques de la graine de soja. Les composés phénoliques peuvent être définis comme des composés ayant au moins un noyau aromatique sur lequel sont fixés un ou plusieurs groupements hydroxyles.

Plusieurs isoflavones ont été isolées dans la graine de soja (figure 1). En tout premier lieu, quatre 
isoflavones ont été détectées dans la graine [1]. II s'agit de la génistine, la daidzine, la daidzéine (aglucone de la daidzine) et la génistéine (aglucone de la génistine). Deux nouvelles isoflavones, la glycitéine et sa forme conjuguée, la glycitéine-7-beta-glucoside (glycitine) ont ensuite été isolées [2]. Plus récemment, les formes acétyles et malonyles ont été détectées : la 6"-O- acétyldaidzine [3], la 6"O- acétylgénistine [4] et la 6"-O- acétylglycitine [5], puis la 6"-O- malonyldaidzine, la 6"-Omalonylgénistine et la 6"-O- malonylglycitine [6].

Cependant, les différentes isoflavones sont inégalement représentées dans la graine de soja. Il semble que la génistine, la daidzine et surtout la malonyldaidzine et la malonylgénistine soient majoritaires [5, $7,8]$. Comme la daidzéine et la génistéine pour le soja, la formonétine (dérivé 4'-O-méthylé de la daidzéine) et la biochanine (dérivé 4'-O-méthylé de la génistéine) pour le pois chiche se trouvent majoritairement sous la forme malonyle dans les tissus de la graine [9]. Les autres isoflavones (glycitine, les formes aglucones, les formes acétyles) sont présentes en très faibles quantités. Les formes acétyles des isoflavones apparaissent semble-t-il à la suite de traitements thermiques $[5,10]$. Dans la graine et dans les produits de première transformation (" lait " de soja, par exemple), les formes acétyles sont donc quasiment absentes. Les isoflavones sont stockées sous des formes " malonyl-conjuguées " dans la vacuole des cellules végétales. Le passage de la forme aglucone à la forme malonyle facilite le transport des isoflavones du tonoplaste (lieu de production) vers la vacuole (lieu de stockage) [11].

Les isoflavones du soja ont surtout été étudiées pour leurs propriétés " alicamenteuses ». Au sein de la plante, elles sont également impliquées dans les mécanismes de réponse à différentes situations du milieu tels que la présence de bactéries symbiotiques [12], l'attaque de pathogènes [13], ou des stress " abiotiques » [14]. De fortes variations de teneur et de composition dans la graine et, par conséquent, dans les aliments à base de soja peuvent être observées suivant les génotypes et les conditions du milieu.

\section{Propriétés « alicamenteuses » des isoflavones du soja}

Deux grands types d'approches ont contribué au développement des recherches portant sur les isoflavones du soja et leur relation avec la santé [15]. La première approche est plutôt d'ordre épidémiologique. En effet, la fréquence des maladies "de société ", telles que les problèmes cardiovasculaires [16] ou l'ostéoporose [17], est moins élevée en Asie qu'en Occident, du fait, notamment, d'une différence importante de régime alimentaire. De plus, les études relatives aux mécanismes régulateurs de la cancérogenèse soulignent l'importance d'agents d'origine alimentaire impliqués dans la régulation de la croissance cellulaire (tels les isoflavones du soja). Plusieurs études montrent, notamment, que le soja (consommé régulièrement par les populations asiatiques) et plus particulièrement les isoflavones présentent plusieurs activités " santé ". À titre d'exemple, les doses ingérées quotidiennement par les individus ont été estimées à 50 à $100 \mathrm{mg}[18,19]$. Ces activités pourraient être impliquées dans des mécanismes de prévention de maladies cardio-vasculaires, de cancers et de problèmes en lien avec la ménopause. Les activités biologiques des isoflavones au sein de l'organisme dépendent, bien entendu, de leur biodisponibilité. Par ailleurs, la bioactivité des isoflavones consommées pourraient présenter, dans certains cas, des effets indésirables. 
L'incidence des maladies cardio-vasculaires (telles que l'athérosclérose) est moindre au Japon, par exemple, qu'en Occident [16]. La différence de régime alimentaire et plus particulièrement la consommation de produits à base de soja (plus importante en Asie) pourraient expliquer (en partie du moins) cette différence. Ainsi, plusieurs composés du soja présentent des propriétés susceptibles de prévenir les maladies cardio-vasculaires. En effet, Carroll [20] et Potter [21, 22] ont mis en évidence l'activité hypocholestérolémique des extraits protéiques de soja. Cette activité a été mise en évidence chez le rat [23], le hamster [24] et I'homme [25]. Une forte cholestérolémie et, plus particulièrement, une forte teneur en LDL (low density lipoproteins), transporteurs du cholestérol, sont considérées comme des facteurs aggravant les risques de maladies cardio-vasculaires. De manière générale, la composition en acides aminés du bol alimentaire pourrait influencer la cholestérolémie. En effet, la méthionine [26] et la cystéine [27] semblent hypercholestérolémiantes tandis que l'arginine présente des propriétés hypocholestérolémiantes [28, 29]. Les protéines de légumineuses, et de soja en particulier, sont très hétérogènes du point de vue de la composition en acides aminés des différentes fractions protéiques $(2 \mathrm{~S}, 7 \mathrm{~S}, 11 \mathrm{~S} \text { et } 15 \mathrm{~S})^{1}$ et ont, par conséquent, été étudiées séparément. Des différences au niveau de l'activité hypocholestérolémiante ont été observées entre les différentes protéines. Ainsi, les protéines 7S [30] et particulièrement la sous-unité beta [31] sont plus actives que les protéines $11 \mathrm{~S}$ au niveau de l'activation des récepteurs LDL. En effet, il semble que l'activité hypocholestérolémiante des extraits protéiques de soja soit liée à l'activation des récepteurs impliqués dans le catabolisme des principaux transporteurs de cholestérol, les LDL [32, 33].

Cependant, un mélange d'acides aminés constitutifs des protéines de soja ne présente pas les mêmes effets qu'un concentrât protéique [34]. II semble donc que d'autres composés présents dans les extraits protéiques (tels que les isoflavones) puissent aussi réduire le taux de cholestérol. Les isoflavones (phyto-œstrogènes) sont des analogues structuraux de l'œstradiol (hormone œstrogène endogène) [35]. Or l'œstradiol présente des propriétés hypocholestérolémiantes. En effet, cette hormone affecte le métabolisme des apoprotéines (constituants protéiques des LDL) [36]. Par conséquent, il semble que deux types de composés pourraient expliquer une large part de l'effet hypocholestérolémiant des produits à base de soja : les protéines et/ou les isoflavones (la daidzéine, la génistéine et leurs métabolites) [37].

Il apparaît que la réduction de la cholestérolémie n'est qu'un des mécanismes de protection potentielle des isoflavones vis-à-vis des problèmes cardio-vasculaires et notamment de l'athérosclérose [38]. L'oxydation des particules LDL est considérée comme une étape préliminaire et indispensable à la formation d'athérome [39]. Des anti-oxydants naturellement présents dans la graine de soja, tels que les isoflavones, pourraient prévenir l'oxydation des particules LDL [40]. De plus, la génistéine inhibe la tyrosine kinase intracellulaire [41]. Or la tyrosine kinase semble impliquée dans la promotion et la progression de l'athérosclérose via la prolifération des cellules musculaires lisses [42] et le développement des plaquettes [43]. Enfin, l'athérosclérose peut être associée à une diminution de la dilatation artérielle (impliquée dans l'infarctus du myocarde) chez les hommes et les femmes ménopausées [44, 45]. Comme les œstrogènes d'origine animale [46], les isoflavones accroissent l'élasticité des artères athérosclérotiques des femelles singes ovariectomisées [47].

Des propriétés des isoflavones sont vraisemblablement impliquées dans la genèse et/ou l'évolution des maladies cardio-vasculaires (l'athérosclérose notamment) en agissant sur le métabolisme des 
lipoprotéines (au niveau de la régulation des récepteurs $L D L$ ) et le maintien d'une vasomotricité normale de la paroi artérielle (réduction de la prolifération des cellules musculaires lisses par action intracellulaire ou estrogen-like). Cependant, certaines études portant sur des patients présentant une cholestérolémie " moyenne " mettent en évidence un effet non significatif d'une supplémentation alimentaire à base d'isoflavones [48, 49].

\section{Ostéoporose et isoflavones du soja}

Au cours de la ménopause, la diminution de la teneur en œstrogènes circulants accélère la perte osseuse. La fréquence des ostéoporoses est différente suivant les régions du globe (plus faible en Asie qu'en Occident) [17]. Une alimentation contenant du soja riche en phyto-œstrogènes pourrait expliquer cette différence. Potter et al. [50] ont montré qu'un régime alimentaire contenant des protéines de soja avec une forte quantité d'isoflavones $(2,5 \mathrm{mg} / \mathrm{g})$ augmentait la densité et le contenu minéral osseux des femmes ménopausées mais uniquement au niveau de la colonne vertébrale. Ces résultats mettent en évidence que l'effet des phyto-œstrogènes du soja est dose-dépendant et siteosseux-spécifique [51]. Une autre étude montre que les isoflavones du soja stimulent la formation osseuse et qu'une consommation régulière, et sur une longue durée, est nécessaire pour augmenter progressivement la masse osseuse [52]. Outre la modulation de la masse osseuse au cours de la ménopause, d'autres symptômes apparaissent pendant cette période. Les bouffées de chaleur (également liées à une diminution du taux d'œstrogènes circulants) représentent un des désagréments les plus couramment rencontrés chez les femmes ménopausées. La fréquence de ce symptôme varie de 70-80 \% pour les femmes ménopausées en Europe [53] à 18 et $14 \%$ en Chine et à Singapour respectivement [54]. Le régime alimentaire riche en phyto-œstrogènes pourrait là encore expliquer, du moins en partie, cette différence. Cependant, les résultats des études portant sur la relation isoflavones-bouffées de chaleur sont encore contradictoires $[53,55]$ et ne permettent pas de conclure sur cette relation.

\section{Cancers et isoflavones du soja}

Comme pour l'ostéoporose ou les accidents cardio-vasculaires, la fréquence des cancers hormonodépendants (de la prostate et du sein, plus particulièrement) est plus faible en Asie qu'en Occident [56, 57]. La différence de régime alimentaire pourrait, ici aussi, expliquer pour partie ces données épidémiologiques. Dans ce cadre, il a été montré que les isoflavones contenues dans les aliments à base de soja présentaient des propriétés particulièrement intéressantes pour la prévention de cancers.

Chez les femmes préménopausées par exemple, les isoflavones, en tant que phyto-œstrogènes, pourraient prévenir l'apparition et le développement de tels cancers grâce à leurs propriétés antagonistes $^{2}$ de celles des œstrogènes endogènes $[58,59]$. Les œstrogènes endogènes stimulent le développement cellulaire. Cette activité a été incriminée dans l'apparition du cancer du sein [60]. De plus, il a été montré que les isoflavones augmentent la durée du cycle menstruel et particulièrement de la phase folliculaire des femmes préménopausées [61]. Puisque le taux mitotique est quatre fois plus élevé pendant la phase lutéinique que pendant la phase folliculaire, les isoflavones peuvent participer à la réduction de la prolifération cellulaire dans le cas des cancers hormono-dépendants chez la femme. Toutefois, il existe d'autres mécanismes d'action des isoflavones du soja ayant un effet préventif potentiel vis-à-vis du développement de cancers [62]. En plus de leur activité œstrogénique, les isoflavones présentent des propriétés anti-oxydantes [63]. Ces propriétés peuvent être protectrices vis-à-vis de stress oxydatifs chroniques responsables de cancérogenèses, comme le tabagisme ou la 
quantité et la qualité du régime alimentaire. Enfin, certaines isoflavones présentent un effet inhibiteur vis-à-vis d'enzymes impliquées dans la prolifération cellulaire [64]. En effet, la génistéine est in vitro un inhibiteur de la tyrosine kinase [41]. Elle semble inhiber également une ADN topo-isomérase [65]. Les tyrosines kinases (action au niveau des facteurs de croissance cellulaire) et les ADN topo-isomérases (action au niveau de la division cellulaire) jouent un rôle important dans la prolifération cellulaire [66]. L'activité de la génistéine sur la limitation de la prolifération cellulaire serait aussi consécutive à d'autres mécanismes, notamment au niveau la régulation du cycle cellulaire [15].

Les isoflavones agiraient donc de façon directe (inhibition d'enzymes impliquées dans la division cellulaire, action au niveau de la régulation du cycle cellulaire) ou plus indirecte (action antiœstrogénique, activité anti-oxydante) sur la prolifération cellulaire au cours de la cancérogenèse.

Toutefois, pour les femmes ménopausées initialement atteintes d'un cancer du sein, la consommation d'une trop grande quantité d'isoflavones ne paraît pas indiquée. En effet les isoflavones, en agissant de façon estrogen-like, peuvent accentuer le développement des cellules cancéreuses [67].

De manière générale, bien que les mécanismes d'action potentiels des isoflavones vis-à-vis du développement de maladies cardio-vasculaires, de cancers et de l'ostéoporose aient été mis en évidence, des études supplémentaires (chez l'animal mais également cliniques) et de grande envergure demeurent nécessaires afin de déterminer l'activité réelle des isoflavones au sein de l'organisme. Par ailleurs, du fait de leurs propriétés (œstrogéniques en particulier), une alimentation riche en isoflavones peut également être soupçonnée d'effets secondaires néfastes.

\section{Effets indésirables des phyto-œestrogènes}

Plusieurs expérimentations ont clairement mis en évidence un effet négatif des phyto-œstrogènes chez différentes espèces animales. Chez le mouton, une réduction importante de la fertilité (clover disease) peut apparaître à la suite d'une alimentation riche en trèfles (pâturage) [68-70]. Les phytoœstrogènes ingérés, la daidzéine et la formononétine, précurseur de la daidzéine notamment [71] ainsi que l'équol, métabolite de la daidzéine [72], sont vraisemblablement à l'origine de ce problème. II existe, toutefois, une grande variabilité de sensibilité vis-à-vis d'une consommation de trèfle en fonction des espèces étudiées. Aucune incidence sur la fertilité n'a été mise en évidence chez des équidés [73] et chez des bovins [74] par exemple. Une différence importante du nombre de récepteurs œstrogéniques chez les ovins (quatre fois supérieure à celui des bovins par exemple) pourrait expliquer cette variation de sensibilité [63].

Setchell et al. [75] ont montré que des problèmes de fertilité chez les guépards en captivité étaient induits par les isoflavones contenues dans les rations alimentaires à base de soja. II semble, en effet, que les félins présentent de manière générale une grande sensibilité vis-à-vis des phyto-œstrogènes. Chez les félins, le taux de conjugaison des œstrogènes au niveau du foie est relativement faible. Le taux de phyto-œstrogènes libres circulants (présentant davantage de propriétés œstrogéniques) est par conséquent plus élevé [64]. Les isoflavones seraient également responsables d'infertilité chez certains rongeurs [76].

Par ailleurs, l'exposition prénatale et néonatale à des composés tels que la génistéine [77] ou le coumestrol [78] influence la différenciation sexuelle chez le rat. Cette influence est dose-dépendante [79]. Il convient cependant de noter que de nombreuses expérimentations ont porté sur le coumestrol 
[64]. L'effet estrogen-like du coumestrol paraît près de 1000 fois plus important que celui de l'équol [80]. Toutefois, le coumestrol n'a pas été détecté dans les graines de soja ou les produits transformés. Seule la graine germée en contient de faibles quantités (de l'ordre de 15 à $80 \mu \mathrm{g} / \mathrm{g}$ de MS). Les plus fortes teneurs, de l'ordre de 0,7 à $5,6 \mathrm{mg} / \mathrm{g}$ de MS), ont été observées chez le trèfle (clover disease) et la luzerne (particulièrement dans les graines germées) [81].

Quoi qu'il en soit, des effets néfastes ont été observés chez différentes espèces animales. Les enfants nourris avec des formules infantiles à base de soja ingèrent quotidiennement de très fortes quantités d'isoflavones. Ces enfants sont particulièrement exposés à des effets néfastes potentiels. Chez ces enfants, la dose d'isoflavones ingérée quotidiennement par unité de poids est 6 à 11 fois supérieure à celle réputée hormono-active chez des adultes [82]. D'après Juniewicz et al. [83], les phytoœstrogènes ont une affinité vis-à-vis des récepteurs œstrogènes de 1/500 et 1/1 000 comparée à celle de l'œstrogène-17beta. Les isoflavones produisent, néanmoins, des réponses œstrogéniques typiques lorsqu'ils sont administrés à des animaux [84]. Cependant, bien qu'un enfant de 4 mois puisse absorber des quantités significatives d'isoflavones, il ne possède pas encore la flore nécessaire pour métaboliser les isoflavones ingérées [85]. En effet, certains métabolites, tels que l'équol issu du métabolisme des isoflavones, sont plus hormono-actifs que les isoflavones elles-mêmes. De plus, l'activité œstrogénique des isoflavones et de leurs métabolites est largement inférieure à celle des œstrogènes endogènes (10 000 à 140000 fois moins) [86]. Enfin, d'autres facteurs tels que le temps de transit (moins long chez l'enfant) peuvent avoir comme conséquence une faible absorption des isoflavones ou de leurs métabolites [86]. Plusieurs études montrent que les enfants, nourris avec des formules infantiles à base de soja, ne présentent pas de différence de croissance et de développement par rapport à ceux consommant du lait de vache [87-90]. De plus, que ce soit en Asie chez des populations consommant régulièrement des produits à base de soja ou en Occident chez des enfants nourris avec des formules infantiles, aucun exemple d'effets néfastes imputables à une consommation riche en isoflavones n'a été répertorié depuis plus de 30 ans [88].

Cependant, des études cliniques à long terme demeurent nécessaires afin de pouvoir conclure de façon scientifique sur l'innocuité des isoflavones.

\section{Absorption et métabolisme des isoflavones}

Compte tenu de la bioactivité des isoflavones, la détermination de leur biodisponibilité paraît indispensable. Malheureusement, le métabolisme des isoflavones n'est pas encore totalement connu chez l'homme [80]. On considère cependant que, après ingestion, les isoflavones conjuguées sont hydrolysées par des enzymes de la flore intestinale et sous $\mathrm{pH}$ acide dans l'estomac. Elles sont absorbées au niveau de l'intestin grêle et probablement du côlon sous forme déconjuguée (aglucones) (figure 2). La dégradation des isoflavones par les bactéries intestinales génère différents métabolites [18]. Le 6'-hydroxy-O-desméthylangolésine est issu de la génistéine et il existe deux voies métaboliques pour la daidzéine produisant soit de la O-desméthylangolésine (O-DMA), soit de l'équol [91]. Ces métabolites sont finalement excrétés dans la bile ou l'urine. Après une excrétion dans la bile, les isoflavones peuvent être hydrolysées une nouvelle fois au niveau du tractus intestinal, métabolisées et réabsorbées grâce à la circulation entéro-hépatique [92]. Le taux d'absorption est différent suivant les isoflavones. En effet, la daidzéine semble plus biodisponible que la génistéine [93]. Les formes conjuguées de la daidzéine sont également davantage biodisponibles que celles de la génistéine [94]. Ces résultats suggèrent que les différences de structure entre la daidzéine et la 
génistéine peuvent engendrer des variations significatives de leur biodisponibilité. De plus, à cause de leur caractère hydrophile plus marqué et de leur poids moléculaire plus important [95], les isoflavones conjuguées sont moins biodisponibles que les aglucones [96]. Bien que, de façon générale, l'absorption et l'excrétion des isoflavones chez l'homme soient fonction de la quantité ingérée [97], des différences au niveau de la réponse métabolique peuvent être observées entre individus. La microflore intestinale, variable suivant les individus à cause de facteurs génétiques ou alimentaires, influence la biodisponibilité des isoflavones [97]. Des différences au niveau de la production des différents métabolites, dérivés des isoflavones ingérées, et notamment au niveau de la transformation de la daidzéine en équol ont également pu être observées. Certains individus (environ $70 \%$ des individus d'une population donnée) sont incapables de métaboliser et d'excréter de l'équol à partir de la daidzéine $[96,98]$. Cette différence inter-individus peut se révéler importante puisque la production d'équol est responsable d'une grande partie des effets biologiques liés à une consommation d'isoflavones. En effet, l'activité œstrogénique de l'équol est largement supérieure à celle de la daidzéine ou du O-DMA [99]. Des différences de capacité à métaboliser les isoflavones selon le sexe des consommateurs ont également été observées [100].

Les variations entre isoflavones concernant leur biodisponibilité et leur métabolisme ne permettent pas, pour l'instant, une détermination rationnelle de la quantité optimale d'isoflavones à ingérer [101]. Toutefois, la connaissance des teneurs et de la composition en isoflavones dans les produits à base de soja est un préalable indispensable à l'établissement de recommandations spécifiques.

\section{Facteurs de variation des teneurs et de la composition en isoflavones dans la graine et les aliments à base de soja}

Les teneurs et la composition en isoflavones dans la graine de soja, mais surtout dans les produits transformés, sont des éléments déterminants dans l'établissement de régimes alimentaires à caractère préventif vis-à-vis de certaines pathologies, par exemple.

Teneur et composition en isoflavones dans la graine de soja

Plusieurs études ont mis en évidence l'importance du facteur " génotypique " pour la teneur en isoflavones [102-104]. Ainsi, par exemple, Eldridge et Kwolek [102] et Tsukamoto et al. [105] rapportent des teneurs allant respectivement de 1,16 à $3 \mathrm{mg} / \mathrm{g}$ et de 0,79 à $3,5 \mathrm{mg} / \mathrm{g}$ suivant les variétés. De plus, il semble que les gammes de variation soient fonction de l'origine des génotypes. En effet, l'étude de huit variétés américaines et de trois variétés japonaises révèle que les teneurs en isoflavones totales varient de 2,05 à 4,02 mg/g pour les variétés américaines et de 1,26 à 2,34 mg/g pour les variétés japonaises [106]. Dans des conditions de culture données, il existe donc une forte variabilité pour la teneur en isoflavones. Cette variabilité semble en lien avec certains caractères intrinsèques de la plante tels que la précocité. En effet, il semble que les variétés précoces aient des teneurs moins élevées que des variétés plus tardives [103]. La teneur en isoflavones caractéristique d'une variété peut être fonction de sa résistance vis-à-vis de certains ravageurs ou pathogènes. Ainsi, la résistance aux pathogènes de certaines variétés pourrait être liée à leurs très fortes teneurs en daidzine et génistine [104].

Le potentiel génotypique pourrait être influencé par des facteurs environnementaux (interaction génotype-milieu). La biosynthèse des isoflavones et, de manière générale, la biosynthèse des composés flavonoïdes sont sous l'influence des conditions du milieu. Ainsi, des variations de teneurs 
en isoflavones pour une même variété ont été observées suivant l'année culturale [104] ou les conditions de culture $[105,107]$. Eldridge et Kwolek [102] observent, par ailleurs, une variation de teneurs de 0,46 à $1,95 \mathrm{mg} / \mathrm{g}$ pour une même variété dans différents lieux de culture. Parmi les conditions environnementales influençant la teneur en isoflavones, les températures pendant le développement de la graine semblent primordiales [103]. De fortes températures tendraient à réduire les teneurs en isoflavonoïdes dans le cotylédon [105]. Les températures durant la croissance de la plante influencent la durée de développement. Une liaison significative entre la teneur en isoflavones et la durée de développement a, ainsi, pu être mise en évidence [108]. Les facteurs culturaux influençant la durée de développement de la plante (contrainte hydrique par exemple) ont également une action au niveau de la teneur en isoflavones des graines à maturité [102].

Les investigations portant sur les variations de la teneur en isoflavones dans la graine de soja mettent en évidence l'importance de l'origine du génotype. Certaines caractéristiques intrinsèques telles que la précocité du génotype pourraient permettre d'expliquer (du moins en partie) le potentiel génotypique d'une variété. Enfin, les facteurs (liés, notamment, aux variations de températures pendant la croissance de la graine) influencent cette teneur.

Teneur et composition dans les aliments à base de soja

La teneur et la composition en isoflavones ont surtout été étudiées sur trois types d'aliments à base de soja : des soyfoods non fermentés et fermentés ainsi que les aliments enrichis en protéines de soja.

\section{Aliments non fermentés}

Le tonyu (jus de soja) et le tofu (caillé de tonyu) sont à l'origine de nombreux soyfoods non fermentés. Il existe plusieurs techniques de fabrication du tonyu et du tofu. Des traitements de " trempage » ou de "blanchiment " (cuisson vapeur) sont souvent utilisés afin de réduire le coût énergétique du broyage et de "présolubiliser " les protéines [109]. Lors de la production de tonyu et plus généralement de soyfoods non fermentés, un traitement thermique est souvent obligatoire afin de limiter l'apparition de mauvais goûts (cas du tonyu) et d'inactiver certains composés antinutritionnels tels que les inhibiteurs de protéinases [109]. Les pellicules et les germes sont parfois séparés du cotylédon. Deux techniques de séparation peuvent être utilisées : soit en présence d'eau après le blanchiment (qui facilite le décollement de la pellicule), soit par des contraintes mécaniques en conditions sèches. Un mélange d'eau et de cotylédons est ensuite broyé. La fraction soluble (tonyu) est séparée de la fraction insoluble (okara) qui constitue un sous-produit généralement valorisé en alimentation du bétail.

Le tofu est un produit texturé obtenu par coagulation des protéines du tonyu en présence de cations $\left(\mathrm{Ca}^{2+}\right.$, notamment) et par pressage (élimination du sérum).

Comme dans la graine, les formes conjuguées sont majoritaires dans le tonyu et dans le tofu [19]. Néanmoins, après un traitement de blanchiment, on observe, dans le tonyu et le tofu, un accroissement (par rapport aux proportions observées dans la graine) des formes aglucones au détriment des formes conjuguées [110,111]. Les formes conjuguées restent cependant majoritaires dans ces produits [112]. Les beta-glucosidases présentes dans la graine jouent un rôle essentiel dans cette modification biochimique en hydrolysant les formes glucosides [113]. Cette activité enzymatique est fonction de la température et du pH (conditions optimales : température de $45^{\circ} \mathrm{C}$, à $\mathrm{pH} 5$ [114]). 
L'implication des beta-glucosidases a été montrée en ajoutant un composé inhibiteur, le gluconodelta-lactone (GDL) dans la solution de blanchiment. Une faible quantité de GDL suffit pour réduire de façon significative les teneurs en daidzéine et en génistéine (formes aglucones, fortement hydrolysées) dans le tonyu [115]. Wang et Murphy [111] ont déterminé le flux des isoflavones au cours de la production de tonyu et de tofu (production sans dépelliculage). II semble que l'utilisation d'une solution de blanchiment lors de la fabrication du tonyu conduit à une perte importante en isoflavones (10 \% des isoflavones de la graine entière). De plus, lors de la séparation tonyu-okara, une majorité des isoflavones est entraînée dans la fraction soluble (tonyu) [116]. Les isoflavones pourraient être liées aux protéines solubles et se concentreraient dans la fraction tonyu [111]. Enfin, de fortes pertes en isoflavones ont été observées lors de la fabrication du tofu. Ces pertes en isoflavones pourraient avoir lieu durant la coagulation des protéines du tonyu. L'association protéines-isoflavones suggérée par Wang et Murphy [111] pourrait alors être rompue et une partie des isoflavones serait entrainée dans le sérum (figure 3).

\section{Aliments fermentés}

Les principaux produits fermentés analysés pour leur teneur en isoflavone sont le tempeh constitué de graines entières fermentées par Rhizopus oligosporus; ce produit est originaire de Malaisie ou d'Indonésie. Le natto à base de graines entières fermentées par Bacillus natto est produit au Japon. Enfin, le miso (nom japonais de la pâte de soja) est obtenu par fermentation d'un mélange de graines de soja et éventuellement de céréale broyées, puis par pressage et séparation du " gâteau » et du surnageant brun (sauce de soja). La principale souche de bactérie utilisée pour la production de sauce de soja est Aspergillus oryzae. Contrairement aux produits non fermentés, le tempeh et le miso contiennent une majorité d'isoflavones aglucones (formes non conjuguées) [19]. Pendant la fermentation, l'action hydrolytique des beta-glucosidases d'origine bactérienne conduit à l'accroissement de la fraction aglucone $[117,118]$. Les isoflavones aglucones ont des propriétés antioxydantes qui permettent une augmentation de la stabilité du produit $[118,119]$. Les propriétés antioxydantes des isoflavones aglucones, notamment, sont dues à leur structure chimique (groupe hydroxyle en position 4') [63]. Dans les aliments fermentés à base de soja, la proportion d'isoflavones malonyles est fortement diminuée par rapport à la graine entière. Lors de la fabrication de miso, cette diminution est de respectivement 51,43 et $75 \%$ pour la malonyldaidzéine, la malonylgénistéine et la malonylglycitéine [120]. L'hydrolyse peut être plus ou moins complète suivant le type d'inoculum employé. Ainsi, dans le cas du tofu fermenté (par Actinomucor), on observe exclusivement l'apparition des aglucones, alors que leur proportion n'est que de $50 \%$ environ dans le miso [121]. II semble, en effet, que les isoflavones de forme malonyle soient transformées en glucosides dans un premier temps, puis en aglucones dans un second temps [106]. Ainsi, dans le natto, les glucosides (formes intermédiaires entre les malonyles fortement conjuguées et les squelettes aglucones) sont majoritaires : 73 \% des isoflavones totales, selon Franke et al. [121]. De nouvelles formes d'isoflavones peuvent apparaître au cours de la fermentation. Ces nouvelles isoflavones constituent un nouveau type d'éléments antioxydants. Klus et al. [122] montrent que trois souches bactériennes parfois utilisées pour la fermentation du tempeh, Brevibacterium epidermis, Micrococcus luteus et Microbacterium aborescens, transforment la glycitéine (isoflavone minoritaire de la graine de soja) en 6,7,4'-trihydroxyisoflavone grâce à une réaction de O-méthylation. Microbacterium aborescens induit aussi la formation de glycitéine à partir de la daidzéine (hydroxylation). Esaki et al. [123] montrent la formation de 8-hydroxydaidzéine et de 8-hydroxygénistéine à partir de la daidzéine et de la génistéine (hydroxylations) lorsque Aspergillus saitoi est utilisé pour la fermentation des graines de soja. Les 
souches Rhizopus les plus couramment employées dans la production de tempeh n'induisent pas ce type de réaction (hydroxylation et O-méthylation) [122]. L'apparition de ces nouvelles formes d'isoflavones demeure, par conséquent, peu courante et spécifique de la souche bactérienne utilisée. En revanche, les processus de fermentation ne semblent pas influer sur la teneur en isoflavones [111]. L'addition plus ou moins importante de céréales, pendant la fabrication de certains produits (miso et sauce de soja), influence la quantité finale d'isoflavones. La teneur en isoflavones pour le miso soja-riz est de $0,7 \mathrm{mg} / \mathrm{g}$ (de matière sèche) contre $1,4 \mathrm{mg} / \mathrm{g}$ pour le miso soja seul [19]. De plus, plusieurs procédés couramment utilisés dans la fabrication des soyfoods fermentés peuvent conduire à une diminution significative de la teneur en isoflavones. Dans le cas du tempeh (figure 4), le blanchiment entraîne une perte de 10 \% des isoflavones de la graine, le dépelliculage, une perte de 1,4 \% environ et la cuisson/élimination de l'eau de cuisson, une perte de $49 \%$ environ [111].

\section{Matières protéiques végétales (MPV) à base de soja}

La farine de soja déshuilée, les isolats et les concentrats protéiques de soja entrent dans la composition de nombreux aliments tels que les analogues de produits carnés ou des formules infantiles et sont très utilisés en tant qu'agents de texture. La figure 5 présente les principales étapes de la fabrication des MPV. Les produits de base peuvent subir plusieurs procédés de transformation (traitements thermiques, texturation) avant leur incorporation dans les aliments. En amont et en aval de la production de ces extraits protéiques, les procédés de fabrication utilisés peuvent influencer la teneur et la composition en isoflavones.

Le déshuilage à l'hexane n'altère pas la composition en isoflavones de la farine de soja. Il semble que les traitements thermiques soient à l'origine de la plus grande partie des modifications de la composition en isoflavones. Un puissant traitement thermique à sec induit la décarboxylation du radical malonyle et conduit à la formation de formes acétyles [121]. Des isoflavones de type acétyle ont été détectées dans des soyflakes grillés [10]. II semble que la nature des composés induits soit directement fonction du type de traitement thermique employé. Une cuisson " à sec " (toastage) entraîne l'apparition de formes acétyles tandis qu'une cuisson " humide " accroît la proportion des formes glucosides (comme dans le cas du blanchiment des graines lors de la fabrication du tonyu) [124]. Par exemple, des formes malonyles, acétyles et glucosides ont été détectées dans des isolats protéiques [105] mais également dans des formules infantiles contenant des isolats [82]. L'apparition des formes acétyles est induite par un traitement thermique à sec pendant le séchage [124]. Par ailleurs, l'accroissement de la proportion des formes glucosides (au détriment d'une partie des formes malonyles initialement présentes) a pour origine l'action des beta-glucosidases du soja (au cours des traitements thermiques humides de l'extraction, par exemple) [111].

Les teneurs en isoflavones dans les isolats et les concentrats sont respectivement 4 à 6 fois et 10 à 20 fois moins élevées que dans la farine de départ [19]. Le processus de déshuilage n'entraîne pas des variations significatives des teneurs en isoflavones dans les MPV. Contrairement à ce qui a pu être observé pour la composition, la teneur en isoflavones n'est pas influencée par les traitements thermiques usuels. Une cuisson excessive (carbonisation) peut toutefois entraîner une diminution de la teneur en isoflavones dans les MPV [123]. Les processus d'extraction des protéines sont à l'origine de la réduction des teneurs. Ainsi, pendant l'extraction en conditions alcalines lors de la production d'isolats, $50 \%$ des isoflavones (initialement présentes dans la farine déshuilée) sont éliminées dans la fraction insoluble [117]. Les lavages à l'éthanol aqueux, souvent utilisé dans la production de 
concentrats et excellent solvant pour les isoflavones, sont vraisemblablement la cause des très faibles teneurs observées dans les concentrats [8].

\section{Notes}

${ }^{1}$ Les diverses fractions protéiques sont distinguées en fonction de leur coefficient de sédimentation $\mathrm{S}$ (pour Svedberg).

${ }^{2}$ Le caractère œstrogen-like ou anti-œstrogénique de l'effet des isoflavones dépend de la quantité d'œstrogène endogène et du nombre de récepteurs œstrogènes.

\section{CONCLUSION et SYNTHESE}

Le soja (notamment sa graine) est particulièrement riche en isoflavones. Ces composés interviennent plus ou moins directement dans les mécanismes de réponse de la plante vis-à-vis d'interactions avec des éléments extérieurs (micro-organismes mais également facteurs abiotiques).

Ces composés peuvent avoir un effet positif dans le cadre de la prévention des maladies cardiovasculaires, de certains cancers (notamment les cancers hormono-dépendants) et des problèmes liés à la ménopause (ostéoporose notamment). L'effet préventif potentiel d'une consommation de soja visà-vis des maladies cardio-vasculaires fait intervenir plusieurs composés de la graine tels que les protéines (composition des différentes fractions) et les isoflavones. Plusieurs propriétés des isoflavones (estrogen-like, anti-oxydation et inhibition de la tyrosine kinase) pourraient être particulièrement impliquées dans ces mécanismes de protection. L'effet préventif potentiel des aliments à base de soja vis-à-vis des problèmes liés à la ménopause (ostéoporose) est directement fonction de l'activité estrogen-like des isoflavones. L'effet préventif potentiel des isoflavones du soja vis-à-vis de plusieurs cancers ferait intervenir leur activité de régulation de la prolifération cellulaire (inhibition de la tyrosine kinase notamment), mais également leurs propriétés anti-oxydantes et estrogen-like (pour les cancers hormono-dépendants).

Un bol alimentaire très riche en isoflavones (par unité de poids) chez les enfants nourris avec des formules infantiles à base de soja ne paraît pas induire des problèmes de croissance et de développement. Plusieurs études sur modèle animal ont, néanmoins, mis en évidence des effets néfastes en lien avec les propriétés œstrogéniques des isoflavones. Il semble, par conséquent, que les études cliniques à long terme portant sur des femmes pré et post-ménopausées, des enfants et des hommes soient nécessaires avant de conclure définitivement sur l'innocuité des isoflavones du soja.

Des différences de taux d'absorption et de métabolisation des isoflavones peuvent être observées entre individus. De plus, des variations de la biodisponibilité et du métabolisme ont également été mises en évidence suivant les différentes isoflavones. Enfin, les différentes isoflavones consommées et métabolisées présentent des activités variables (notamment estrogen-like). 
De façon générale, l'effet biologique des isoflavones dépend, par conséquent :

- des isoflavones consommées (teneur et composition des produits transformés et de la matière première) ;

- de la bio-disponibilité des isoflavones consommées ;

- de l'activité des isoflavones consommées et métabolisées.

Dans le cadre de la production de soja destiné à la production d'aliments-santé, l'étude des teneurs et de la composition dans la matière première s'inscrit dans une démarche d'une meilleure valorisation des isoflavones contenues dans les produits et coproduits. Des études ont mis en évidence l'importance du facteur génotypique et particulièrement de la précocité ainsi que de l'origine du génotype. Certaines études ont également montré l'influence des conditions de culture (telles que la date de semis, l'alimentation hydrique ou le lieu de culture).

Les procédés de transformation influencent la teneur et la composition en isoflavones des soyfoods (tableau).

Les études portant sur la teneur et la composition en isoflavones de toutes les composantes de la chaîne de production de soyfoods s'inscrivent dans le cadre d'une meilleure valorisation des composés santé des différents produits.

\section{Remerciements}

Nous tenons tout particulièrement à remercier l'entreprise Nutrition \& Soja (Revel, France), I'ONIDOL (Paris, France) et la région Midi-Pyrénées.

\section{REFERENCES}

1. WALTER ED (1941). Genistin (an isoflavone glucoside) and its aglucone, genistein, from soybean. J Am Chem Soc, 63 : 3273-6.

2. NAIM M, GESTETNER B, BONDI A, BRIK Y (1973). A new isoflavone from soya beans. Phytochem, 12 : 169-70.

3. OHTA N, KUWATA G, AKAHORI H, WATANABE T (1979). Isoflavonoid constituents of soybean and isolation of a new acetyldaidzin. Agric Biol Chem, 43 : 1415-9.

4. OHTA N, KUWATA G, AKAHORI H, WATANABE T (1980). Isolation of a new isoflavone acetyl glucoside, 6"-O-acetylgenistin, from soybean. Agric Biol Chem, 44 : 469-70.

5. KUDOU S, SHIMOYAMADA M, IMARA T, UCHIDA T, OKUBO K (1991). A new isoflavone glycoside in soybean seeds (Glycine max Merrill), glycitein 7-O-beta-D-(6"-O-acetyl)-glucopryranoside. Agric Biol Chem, 55 : 859-90.

6. KUDOU S, FLEURY Y, WELTI D, et al. (1991). Malonyl isoflavone glycosides in soybean seeds (Glycine max L. Merril). Agric Biol Chem, 55 : 2227-33. 
7. ELDRIDGE AC (1982). Determination of isoflavones in soybean flours, protein concentrates and isolates. J Agric Food Chem, 30 : 353-5.

8. WANG HJ, MURPHY PA (1994). Isoflavone composition of American and Japanese soybean in lowa : effects of variety, crop year, and location. J Agric Food Chem, 42 : 1674-7.

9. KESSMAN H, BARZ W (1987). Accumulation of isoflavones and pterocarpan phytoalexins in cell suspension cultures of different cultivars of chickpea (Cicer arietinun). Plant Cell Rep, $6: 55-9$.

10. FARMAKALIDIS TL, MURPHY (1985). Isolation of 6"-O-acetylgenistin and 6"-O-acetyldaidzin from toasted defatted soyflakes. J Agric Food Chem, 33 : 385-9.

11. TEUSCH M, FORKMANN G (1987). Malonyl-coenzyme a : anthocyanidin 3-glucoside malontransferase from flowers of Callistephus chinensis. Phytochem, 26 : 2181-3.

12. KOSSLAK RM, BOOKLAND R, BARKEI J, PAARENN H, APPELBAUM ER (1987). Induction of Bradyrhizobium japonicum common nod genes by isoflavones isolated from Glycine max. Proc Natl Acad Sci USA, 84 : 7428-32.

13. KRAMER RP, HINDORF H, JHA HC, KALLAGE J, ZILLIKEN F (1984). Antifungal activity of soybean and chickpea isoflavones and their reduced derivatives. Phytochem, $23: 207-32$.

14. GRAHAM TL, GRAHAM MY (1991). Glyceollin elicitors induce major but distinctly different shifts in isoflavonoid metabolism in proximal and distal soybean cell populations. Mol Plant Microbe Interact, 3 : 157-66.

15. KIM H, PETERSON GT, BARNES S (1998). Mechanism of action of the soy isoflavone genistein : emerging role for its effects via transforming growth factor b signaling. Am J Clin Nutr, 68 : S1418-30.

16. BEAGLEHOLE R (1990). International trends in coronary heart disease mortality, morbidity, and risk factors. Epidemiol Rev, $12: 1-15$.

17. COOPER C, CAMPION G, MELTON JL (1992). III. Hip fractures in the elderly : a world wide projection. Osteoporos Int, $2: 285-9$.

18. ALDERCRUTZ H, HONJA H, HIGASHI A, et al. (1991). Urinary excretion of lignans and isoflavonoid phytoestrogens in Japanese men and women consuming a traditional Japanese diet. Am J Clin Nutr, 54 : 1093-100.

19. COWARD L, BARNES LC, SETCHEL KDR, BARNES S (1993). Genistein, daidzein, and their betaglycoside conjugates : anti-tumor isoflavones in soybean foods from American and Asian diets. J Agric Food Chem, 41 : 1961-7.

20. CARROLL KK, KUROWSKA EM (1995). Soy consumption and cholesterol reduction : review of animal and human studies. J Nutr, 125 : S594-7.

21. POTTER SM (1995). Overview of proposed mechanism for the hypocholesterolemic effect of soy. $J$ Nutr, 125 : S606-11. 
22. POTTER SM (1996). Soy protein and serum lipids. Curr Opin Lipidol, $7: 260-4$.

23. KIRK EA, SUTHERLAND P, WANG SA, CHAIT A, LEBOEUF RC (1998). Dietary isoflavones reduce plasma cholesterol and athersclerosis in C57BL/6 mice but not LDL receptor-deficient mice. J Nutr, 128 : 954-9.

24. TSAI PJ, HUANG PC (1999). Effects of isoflavones containing soy protein isolate compared with fish protein on serum lipids ands suceptibility of low density lipoprotein and liver lipids to in vitro oxidation in hamsters. J Nutr Biochem, 10 : 631-7.

25. WONG WW, SMITH EO, STUFF JE, HACHEY DL, HEIRD WC, POWNELL HJ (1998). Cholesterollowering effect of soy protein in normocholesterolemic and hypercholesterolemic men. Am J Clin Nutr, 68 : S1385-9.

26. SUGIYAMA K, KUMAZAWA A, ZHOU H, SAEKI S (1998). Dietary methionine level affects linoleic acid metabolism though phosphatidylethanolamine $\mathrm{N}$-methylation in rats. Lipids, 33 : 235-41.

27. MORITA T, OH-HASHI A, TAKEI K, IKAI M, KASAOKA S, KIRIYAMA S (1997). Cholesterol-lowering effects of soybean, potato and rice proteins depend on their low methionine contents in rats fed a cholesterol-free purified diet. J Nutr, 127 : 470-7.

28. KUSROWSKA EM, CARROLL KK (1994). Hypercholesterolemic responses in rabbits to selected groups of dietary essential amino acids. J Nutr, 124 : 364-70.

29. CARROLL KK, KUROWSKA EM (1995). Soy consumption and cholesterol reduction : review of animal and human studies. J Nutr, 125 : S594-7.

30. LOVATI MR, MANZONI C, CORSINI A, GRANATA A, FUMAGALLI R, SIRTORI CR (1996). 7S globulin from soybean is metabolized in human cell cultures by a specific uptake and degradation system. $J$ Nutr, 126 : 2831-42.

31. LOVATI MR, MANZONI C, GIANAZZA E, SIRTORI CR (1998). Soybean protein products as regulators of liver low-density lipoprotein receptors. I. Identification of active beta-conglycinin subunits. J Agric Food Chem, $46: 2474-80$.

32. LOVATI MR, MANZONI C, CANAVESI A, et al. (1987). Soybean protein diet increases low density liprotein receptor activity in mononuclear cells from hypercholesterolemic patients. J Clin Invest, 80 : 1498-502.

33. SIRTORI CR, LOVATI MR, MANZONI C, MONETTI M, PAZZUCCONI F, GATTI E (1995). Soy and cholesterol reduction : clinical experience. J Nutr, 125 : S598-605.

34. HUFF MW, CARROLL KK (1980). Effects of dietary proteins and amino acid mixtures on plasma cholesterol levels in rabbits. J Nutr, $110: 1676-85$.

35. BALMIR F, STAACK R, JEFFREY E, BERBER-JIMENEZMDR, WANG L, POTTER SM (1996). An extract of soy flour influences serum cholesterol and thyroid hormones in rats and hamsters. J Nutr, $126: 3046-$ 53. 
36. DEELEY RG, TAM SP, ARCHER TK (1985). The effects of estrogen on apoliprotein synthesis [review]. Can J Biochem Cell Biol, $63: 882-9$.

37. POTTER SM (1998). Soy protein and cardiovascular disease : the impact of bioactive components in soy. Nutr Rev, $56: 231-5$.

38. ANTHONY MS, CLARKSON TB, WILLIAMS JK (1998). Effects of soy isoflavones on atherosclerosis : potential mechanisms. Am J Clin Nutr, 68 : S1390-3.

39. DEJAGER S, CHAPMAN J (1996). Oxydation des lipoprotéines de basse densité et athérogenèse. $O C L, 3: 1995-9$.

40. TIKKANEN MJ, WÄHÄLÄ K, OJALA S, VIHMA V, ADLERCREUTZ H (1998). Effect of soybean phytoestrogen intake on low density lipoprotein oxidation resistance. Proc Natl Acad Sci USA, 95 : 3106-10.

41. AKIYAMA T, ISHIDA J, NAKAGAWA S, et al. (1987). Genistein, a specific inhibitor of tyrosine-specific protein kinases. J Biol Chem, 262 : 5592-5.

42. GAUDETTE DC, HOLUB BJ (1990). Effect of genistein, a tyrosine kinase inhibitor, on U46619induced phosphoinositide phosphorylation in human platelets. Biochem Biophysical Res Com, 170 : 238-42.

43. SHIMOKADO K, UMEZAWA K, OGATA J (1995). Tyrosine kinase inhibitors inhibit mutiple steps of the cell cycle of vascular smooth muscle cells. Exp Cell Res, $220: 266-73$.

44. GILLIGAN DM, QUYYUMI AA, CANNON RO (1994). III. Effects of physiological levels of estrogen on coronary vasomotor function in postmenopausal women. Circulation, $89: 2545-51$.

45. HERRINGTON DM, BRADEN GA, WILLIAMS JK, MORGAN TM (1994). Estrogen modulates coronary vasomotor responses in postmenopausal women with early atherosclerosis. Am J Cardiol, 73 : 951-2.

46. WILLIAMS JK, ADAMS MR, KLOPFENSTEIN HS (1990). Estrogen modulates responses of atherosclerotic coronary arteries. Circulation, 81 : 1680-7.

47. HONORÉ EK, WILLIAMS JK, ANTONY MS, CLARKSON TB (1997). Soy isoflavones enhance coronary vascular reactivity in atherosclerotic female macaques. Fertil Steril, 67 : 148-54.

48. GOODERHAM MJ, ALDERCREUTZ H, OJALA ST, WAHALA K, HOLUB B (1996). A soy protein isolate rich in genistein and daidzein and its effects on plasma isoflavone concentrations, platelet aggregation, blood lipids and fatty acide composition of plasma phospholipid in normal men. J Nutr, 126 : 2000-6.

49. HODGSON JM, PUDDEY IB, BEILIN LJ, MORI TA, CROFT KD (1998). Supplementation with isoflavonoid phytoestrogens does not alter serum lipid concentrations : a randomized controlled trial in humans. J Nutr, $128: 728-32$. 
50. POTTER SM, BAUM JA, TENG H, STILLMAN RJ, SHAY NF, ERDMAN JW (1998). Soy protein and isoflavones : their effects on blood lipids and bone density in postmenopausal women. Am J Clin Nutr, 68 : S1375-9.

51. ANDERSON JJB, GARNER SC (1997). The effects of phytoestrogens on bone. Nutr Res, 17 : 1617-32.

52. ARJMANDI BH, GETLINGER MJ, GOYAL NV (1998). Role of soy protein with normal or reduced isoflavone content in reversing bone loss induced by ovarian hormone deficiency in rats. Am J Clin Nutr, 68 : S1358-63.

53. KNIGHT DC, EDEN JA (1996). A review of the clinical effects of phytoestrogens. Obstet Gynecol, 87 : 897-904.

54. BOULET MJ, ODDENS BJ, LEHERT P, VEMER HM, VISSER A (1994). Climacteric and menopause in seven south-east Asian countries. Maturitas 19 : 157-76.

55. BINGHAM SA, ATKINSON C, LIGGINS J, BLUCK L, COWARD A (1998). Phytoestrogens : where are we now ? Br J Nutr, 79 : 393-406.

56. SEVERSON RK, NOMURA AMY, GROVE JS, STEMMERMAN GN (1989). A prospective study of demographics, diet and prostate cancer among men of Japanese ancestry in Hawaii. Cancer Res 49 : 1857-60.

57. LEE HP, GOURLEY L, DUFFY SW, ESTEVE J, LEE J, DAY NE (1991). Dietary effects on breast cancer risk in Singapore. Lancet, $337: 1197-200$.

58. SETCHELL KDR, BORRIELLO SP, HUME P, KIRK DN, AXELSON M (1984). Non-steroidal estrogens of dietary origin : possible roles in hormone dependent disease. Am J Clin Nutr, 40 : 569-78.

59. MOLTENI A, BRIZIO-MOLDENI L, PERSKY V (1995). In vitro hormonal effects of soybean isoflavones. J Nutr, 125 : S751-6.

60. BRECKWOLDT M, KECK C, KARCK U (1995). Benefits and risks of hormone replacement therapy (HRT). J Steroid Biochem Molec Biol, 53 : 205-8.

61. CASSIDY A, BINGHAM S, SETCHELL K (1994). Biological effects of a diet of soy protein rich in isoflavone on the menstrual cycle of premenopausal women. Am J Clin Nutr, 60 : 333-40.

62. MESSINA M, BARNES S (1991). The role of soy products in reducing risk of cancer. $J$ Natl Cancer Inst, $83: 541-6$.

63. WEI H, BOWEN R, CAI Q, BARNES S, WANG Y (1995). Antioxidant and antipromotional effects of the soybean isoflavone genistein. PSEBM, $208: 124-30$.

64. RICKARD SE, THOMPSON LU (1997). Phytoestrogens and lignans : effects on reproduction and chronic disease. In antinutrients and phytochemicals in food. Am Chemical Society, 662 : 273-93.

65. CONSTANTINOU A, KIGUCHI K, HUBERMAN E (1990). Induction of differentiation and DNA strand breakage in human HL-60 and K562 leukemia cells by genistein. Cancer Res, 50 : 2618-24. 
66. WEIL JH (1995). Régulation du métabolisme cellulaire. In : Biochimie générale. Paris : Éditions Masson : 477-88.

67. HSIEH CY, SANTELLE RC, HASLAM SZ, HELFERICH W (1998). Estrogenic effects of genistein on the growth of estrogen receptor-positive human breast cancer (MCF-7) cells in vitro and in vivo. Cancer Res, $58: 3833-8$.

68. BENNETTS HW, UNDERWOOD EJ, SHIER FL (1946). A specific breeding problems of sheep on suterranean pastures in werten austalia. Aust Vet, $\mathrm{J} 22$ : 2-12.

69. BRADEN AWH, HART NK, LAMBERTON JA (1967). The estrogenic activity and metabolism of certien isoflavones in sheep. Aust J Agric Res, 18 : 335-48.

70. SHUTT DA, BRADEN AWH. (1968). The significance of equol in relation to the estrogenic responses in sheep ingesting clover with a high formononetin content. Austr J Agric Res, 19 : 545-53.

71. MILLINGTON AJ, FRANCIS CM, MCKEOWN NR (1964). Wether bioassay of annual pasture legumes. J Nutr, 125 : S751-6.

72. SHUTT DA, COX RI (1972). Steroid and phytoestrogen binding to sheep uterine receptors in vitro. Endocrinology, 52 : 299-310.

73. MONTFORT SL, THOMSON MA CZEKALA NM, KASMAN LH, SCHAKLETON CH (1984). Identification of a non-steroidal estrogen, equol, in the urine of pregnant macaques : correlation with steroidal estrogen excretion. J Steroid Biochem, 20 : 869-76.

74. BRADEN AWH, THAIN RI, SHUTT DA (1971). Comparison of plasma phytoestrogen levels in sheep and cattle after feeding on fresh clover. Aust J Agric Res, 22 : 663-70.

75. SETCHELL KDR, GOSSELIN SJ, WELSH MB, JOHNSTON JO, BALISTRERI WF (1987). Dietary estrogens a probable cause of infertility and liver disease in captive cheetahs. Gastroenterology, 93 : 225-33.

76. FARMAKALIDIS TL, HATHCOK JN, MURPHY P (1985). Oestrogenic potency of genistin and daidzein in mice. Food Chem Toxicol, $23: 741-5$.

77. LEVY JR, FABER KA, AYYASH L, HUGHES CLJ (1995). The effect of prenatal exposure to the phytoestrogen genistein on sexual differentiation in rats. Proc Soc Exp Biol Med, 208 : 60-6.

78. WHITTEN PL, NAFTOLIN F (1992). Effect of phytoestrogen diet on estrogen-dependant reproductive processes in immature female rat. Steroids, $57: 56-61$.

79. FABER KA, HUGHES CL (1993). Dose response characteristics of neonatal exposure to genistein on pituitary responsiveness to gonadotropin releasing hormone and volume of the sexual dimorphic nucleus of the preoptic area (SDN-POA) in postpubertal castrated female rats. Repro Toxicol, $7: 35-9$.

80. KURZER MS, XU X (1997). Dietary phytoestrogens. Ann Rev Nutr, 17 : 353-81.

81. FRANKE A, CUSTER LJ, CERNA CM, NARALA KN (1995). Rapid HPLC analysis of dietary phytoestrogens from legume and from human urine. Proc Soc Exp Biol Med, 208 : 18-26. 
82. SETCHELL KDR, NERCHEMIAS-ZIMMER L, CAI J, HEUBI JE (1997). Exposure of infants to phytoestrogens from soy infant formulas. Lancet, $350: 23-7$.

83. JUNIEWICZ PE, PALLANTE MORELL S, MOSER A, EWING LL (1988). Identification of phytoestrogens in the urine of male dogs. J Steroid Biochem, 31 : 987-94.

84. CASSIDY A (1996). Physiological effects of phy-oestrogens in relation to cancer and other human health risk. Proc Nutr Soc, 55 : 399-417.

85. SETCHELL KDR, ZIMMER-NERCHEMIAS L, CAI J, HEUBI JE (1998). Isoflavone content of infant formulas and the metabolic fate of these phytoestrogens in early life. Am J Clin Nutr, 68 : S1453-61.

86. KLEIN KO (1998). Isoflavones, soy-based infant formulas, and relevance to endocrine function. Nutr Rev, $56: 163-204$.

87. AGGET PJ, HASKE F, HEINE W (1990). Comment on the composition of soy protein-based infant and follow-up formulas. Acta Pediatr Scand, 79 : 1001-5.

88. MURPHY PA, SONG T, BUSEMAN G, BARUA K (1997). Isoflavones in soy-based infant formulas. J Agric Food Chem, 45 : 4635-8.

89. VENKATARAMAN PS, LUHAR H, NEYLAN MJ (1992). Bone mineral metabolism in full-term infants fed human milk, cow's milk-based, and soy-based formulas. Am J Dis Child, 146 : 1302-5.

90. BRAINBRIDGE RR, MIMOUNI F, TSANG RC (1993). Bone mineralization in the first year of life in infants fed human milk, cow milk formula, or soy-based formula. J Pediatr, 122 : 348-54.

91. JOANNOU GE, KELLY GE, REEDER AY, WARING M, NELSON C (1995). A urinary profile study of dietary phytoestrogens : the identification and mode of metabolism of new flavonoids. I Steroid Biochem Molec Biol, 54 : 167-84.

92. GRIFFITHS LA, BARROWS A (1972). Metabolism of flavonoid compounds in germ-free rats. Biochem J, $130: 1161-2$.

93. XU W, WANG HJ, MURPHY PA, COOK L, HENDRICH SA (1994). Daidzein is more bioavailable soymilk isoflavone than is genistein in adult women. $J$ Nutr, $126: 871-7$.

94. KING RA (1998). Daidzein conjugates are more bioavailable than genistein conjugates in rats. Am J Clin Nutr, 68 : S1496-9.

95. BROWN JP (1988). Hydrolysis of glycosides and esters. In : ROWLANG IR, ed. Role of the gut flora in toxicity and cancer. San Diego : Academic press : 109-44.

96. HUTCHINS AM, SLAVINS JL, LAMPE JW (1995). Urinary isoflavonoid phytoestrogen and lignan excretion after consumption of fermented and unfermented soy products. J Am Diet Assoc, 545-51.

97. XU X, HARRIS KS, WANG HJ, MURPHY PA, HENDRICH S (1995). Bioavailability of soybean isoflavones depends upon gut microflora in women. J Nutr, 125 : 2307-15. 
98. KELLY GE, JOANNOU GE, NELSON C, REEDER AY, WARING MA (1993). Metabolites of dietary (soya) isoflavones in human urine. Clin Chim Acta, 223 : 9-22.

99. PRICE KR, FENWIRK GR (1985). Naturally occurring estrogens in foods : a review. Food Addit Contam, $2: 73-106$.

100.LU LJW, ANDERSON KE (1998). Sex and long term soy diets affect the metabolism and excretion of soy isoflavones in humans. Am J Clin Nutr, 68 : S1500-4.

101. SLAVIN JL, KARR SC, HUCHINS AM, LAMPE JW (1998). Influence of soybean processing, habitual diet and soy dose on urinary isoflavonoid excretion. Am J Clin Nutr, 68 : S1492-5.

102. ELDRIDGE AC, KWOLEK F (1983). Soybean isoflavones : effect of environment and variety on composition. J Agric Food Chem, 31 : 394-6.

103. KITAMURA K, AGATE K, KICHUCHI A, KUDOU S, OKUBO K (1991). Low isoflavone content in early maturing cultivars, so called summer-type soybeans (Glycine max (L) Merril). Jpn J Breeding, 41 : 651-4.

104. CARRÃO-PANIZZI MC, KITAMURA K (1994). Isoflavones contents in Brazilian soybean cultivars. Breeding SC, 45 : 295-300.

105. TSUKAMOTO C., SHIMADA S, IGITA K, et al. (1995). Factors affecting isoflavone content in soybean seeds : changes in isoflavones, saponins and composition of fatty acids at different temperatures during the seeds development. J Agric Food Chem, 43 : 1184-92.

106. Wang HJ, Murphy PA (1994b). Isoflavone content in commercial soybean foods diets. J Agric Food Chem, 41 : 1961-7.

107. AUSSENAC T, LACOMBE S, DAYDE J (1998). Quantification of isoflavones by capillary zone electrophoresis in soybean seeds : effects of variety and environment. Am J Clin Nutr, 68 : S1480-5.

108. LACOMBE S, AUSSENAC T, LA DROITTE P, DAYDE J (1999). Effects of environmental factors on isoflavone content and composition in soybean seeds. In : Proceedings of the World soybean research conference VI, Chicago, Illinois, USA, 709.

109. TANTEERATARM K, WIJETATNE WB, NELSON AI, WEI LS (1994). Problems, remedies and prospects of soybean processing. Processing of the World soybean research conference $V$, Chiang Mai, Thailand : 461-9.

110. HA EYW, MORR CV, SEA A (1992). Isoflavone aglucones and volatile organic compounds in soybean ; effects of soaking treatment. J Food Sc, $57: 1992$.

111. WANG HJ, MURPHY PA (1996). Mass balance study of isoflavones during soybean processing. J Agric Food Chem, 44 : 2377-83.

112. BARNES S, KIRK M, COWARD L (1994). Isoflavones and their conjugates in soy foods : extraction conditions and analysis by HPLC-mass spectrometry. J Agric Food Chem, 42 : 2466-74. 
113. MATSUURA M, OBATA A, FUKUSHIMA D (1990). Long life packed tofu in United States. Proceeding of the international conference on soybean processing and utilization (Japan Part), Congzuling, China : $37-40$.

114. MATSUURA M, OBATA S (1993). beta-glucosidases from soybeans hydrolyze daidzin and genistin. J Food Sci, 58 : 144-7.

115. MATSUURA M, OBATA A, FUKUSHIMA D (1989). Objectionable flavor of soy milk developed during the soaking of soybean and its control. J Food Sci, 54 : 602-5.

116. LACOMBE S, AUSSENAC T, LA DROITTE P, DAYDÉ J (1999). Isoflavones, " health » compounds in soybean seeds and soyfoods : variation of content and composition in raw material and soy products. In : Proceedings of the World soybean research conference VI, 4-7 August 1999, Chicago, USA : 696.

117. MURAKAMI H, ASAKAWA T, TERAO J, MATSUSHITA S (1984). Antioxidative stability of tempeh and liberation of isoflavones by fermentation. Agric Biol Chem, 48 : 2971-5.

118. MURYAMI W (1995). Isoflavones in tempe. Asian Food J, 10 : 99-102.

119. GYÖRGY P, MURATA K, IKEHATA H (1964). Antioxydants isolated from fermented soybean (tempeh). Nature, $203: 870-2$.

120. BUSEMAN G, MURPHY P, BARUA K, SONG T (1996). Redistribution of soy isoflavones during miso fermentation. In : Book of abstract of the IFT annual meeting $: 23$.

121. FRANKE A, HANKIN J, MIMI CY, MASKARINEC G, LOW SW, CUSTER LJ (1999). Isoflavone levels in soy foods consumed by multiethnic populations in Singapore and Hawaii. J Agric Food Chem, 47 : 977 86.

122. KLUS K, BÖRGER-PAPENDORF G, BARZ W (1993). Formation of 6, 7, 4'-trihydroxyisoflavone (factor 2) from soybean seed isoflavones by bacteria isolated from tempe. Phytochem, $34: 979-81$.

123. ESAKI H, ONOZAKI H, MORIMITSU Y, KAWAKISHI S, OSAWA T (1998). Potent antioxidative isoflavones isolated from soybeans fermented with Aspergillus saitoi. Biosci Biotechnol Biochem, 62 : 740-6.

124. COWARD L, SMITH M, KIRK M, BARNES S (1998). Chemical modification of isoflavones in soyfoods during cooking and processing. Am J Clin Nutr 68 : S1486-91. 


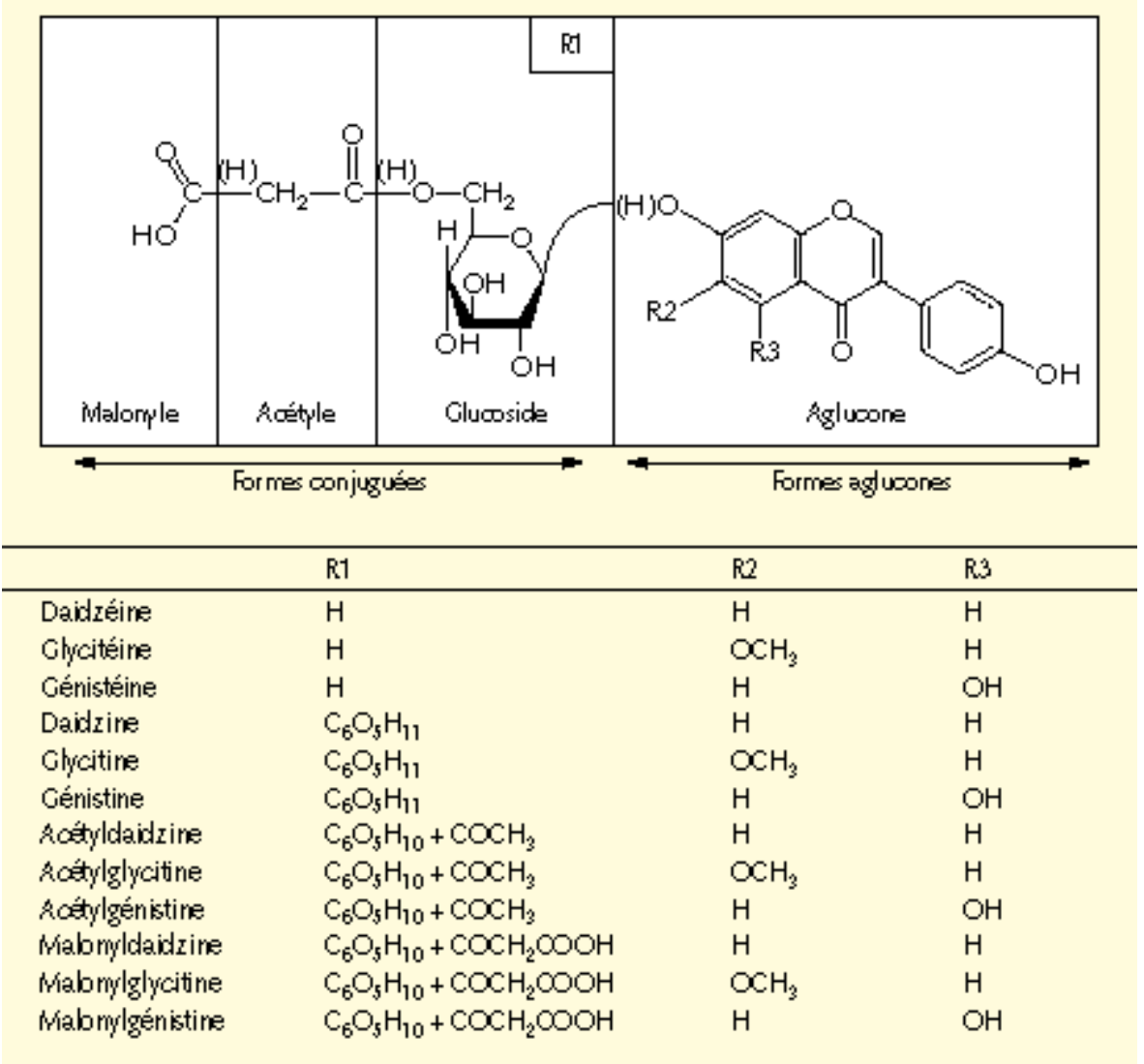

Figure 1. Structure des isoflavones du soja (d'après Kudou et al. [6]). 


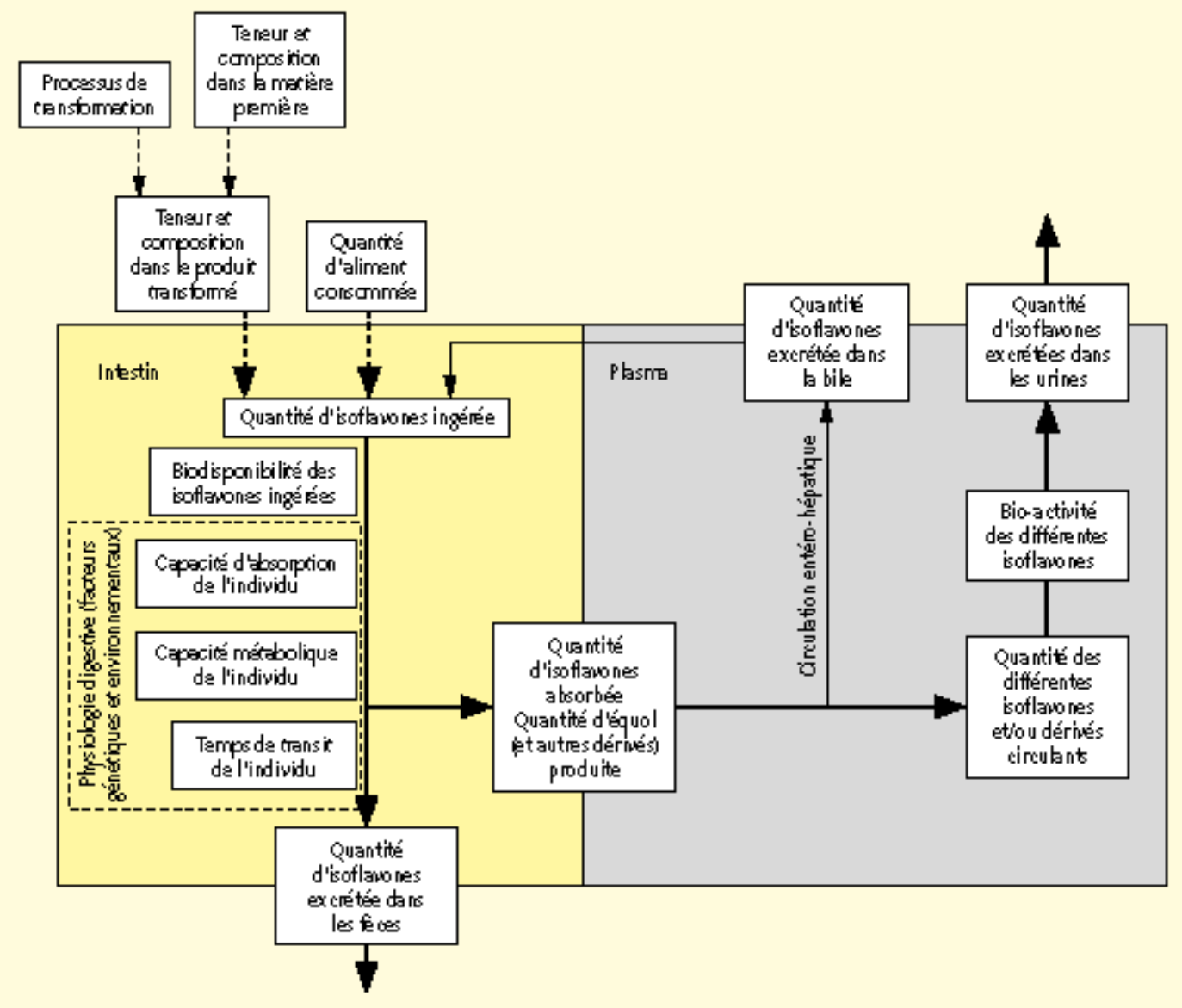

Figure 2. Hypothèses concernant l'absorption et le métabolisme des isoflavones. 


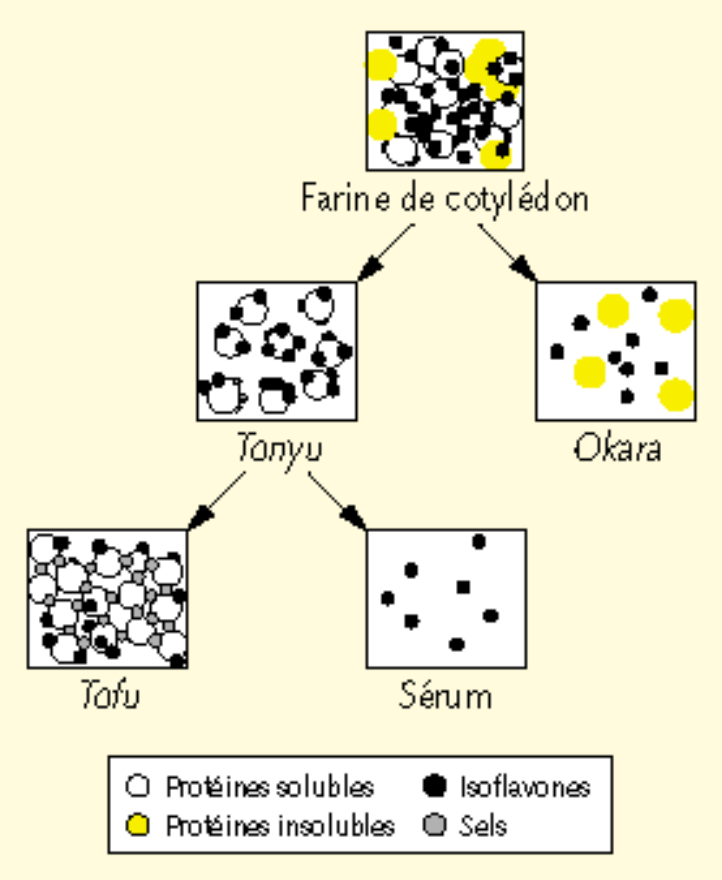

Figure 3. Hypothèse concernant le flux des isoflavones au cours de la production de tonyu et de tofu (d'après Wang et Murphy [106]).

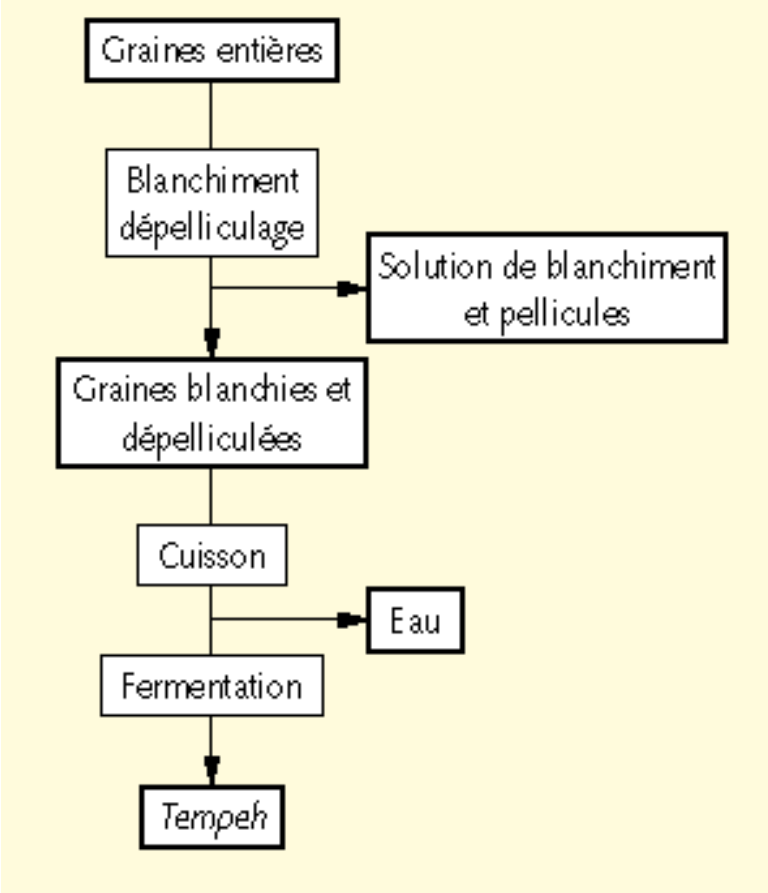

Figure 4. Fabrication du tempeh. 


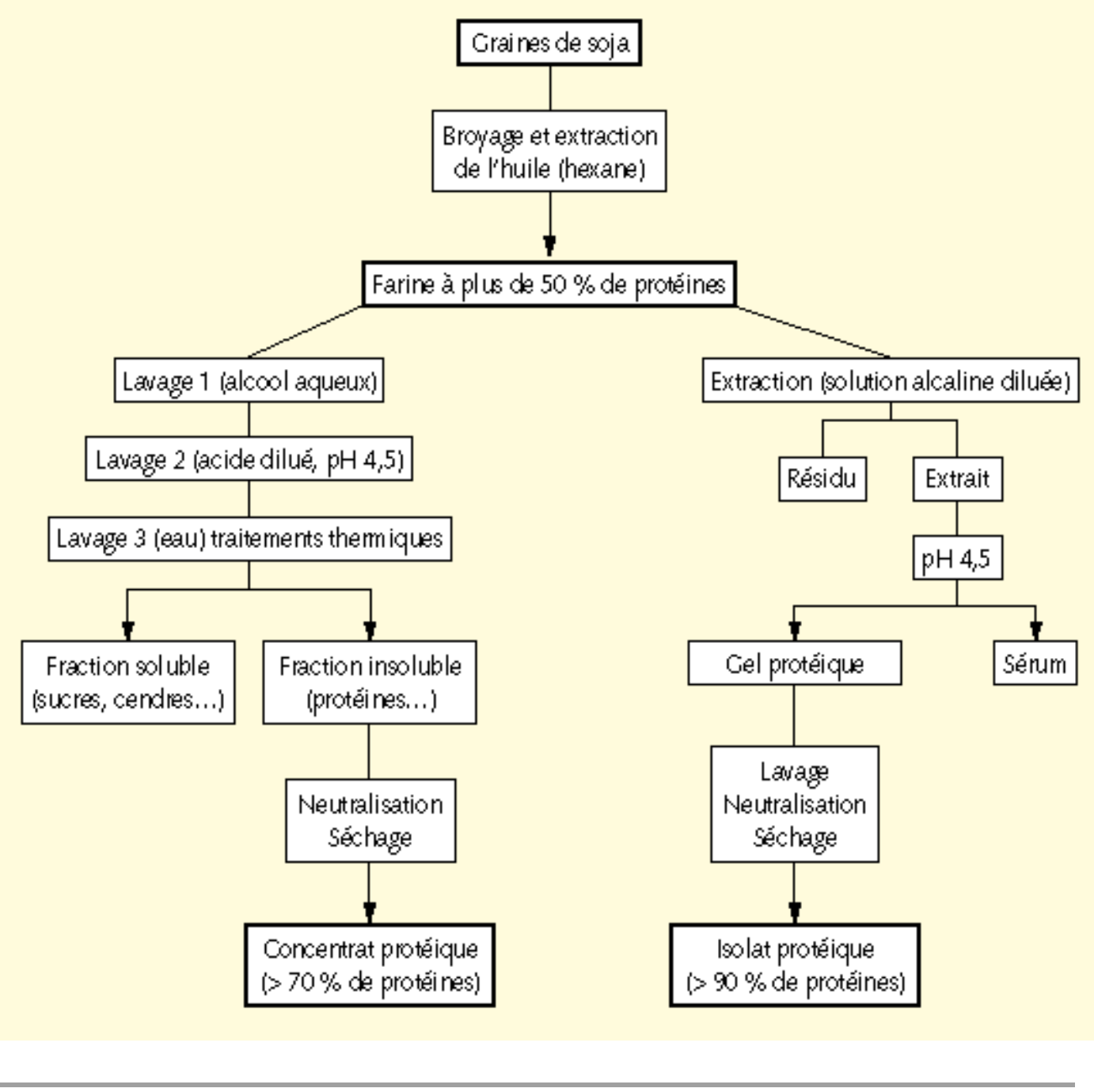

Figure 5. Schéma de la production de farines, d'isolats et de concentrats protéiques de soja. 


\begin{tabular}{|c|c|c|c|}
\hline Produit & Procédés & Effets sur la composition & Effets sur la teneur \\
\hline \multirow[t]{2}{*}{ Tonyu } & Blanchiment & Diminution de la fraction conjuguée [107] & Pertes significatives [105] \\
\hline & Extraction de la fraction soluble & & Pertes peu importantes [105] \\
\hline Tofu & Coagulation des protéines & & Perte importante [105] \\
\hline \multirow[t]{3}{*}{ Produits fermentés } & Dépelliculage & & Peu de pertes [105] \\
\hline & Fermentation & Accroissement de b fraction aglucone $[111,112]$ & Pasd'effet établi \\
\hline & & Nouveaux dérivés possibles $[116,117]$ & \\
\hline \multirow[t]{3}{*}{ MPV } & Tra itement thermique à sec & Accroissement fraction acétyle [118] & Pasd'effet \\
\hline & Extraction en conditions alca lines & & Pertes importantes [112] \\
\hline & Extraction à l'alcool aqueux & & Pertes très importa ntes [8] \\
\hline
\end{tabular}

Tableau. Effets des procédés de production de tonyu, de tofu, de produits fermentés ou de MPV sur la teneur et la composition en isoflavones. 